\title{
What's interesting?
}

\author{
Peter Klaus
}

Published online: 16 November 2010

(C) Springer-Verlag 2010

In a paper that was published in 1971, the American sociologist Murray S. Davis ("That's Interesting!" in: Philosophy of the Social Sciences I, 1971, pp. 309-344) raised a question which should be extremely important to authors of scientific work and to editors of academic journals: Authors want their research to be noticed, utilized, and quoted. And editors want to anticipate which kinds of manuscripts will get attention and will be considered worthwhile reading by their audiences when reviewing and selecting submissions for publication.

Both-authors and editors-need to know what it is that may make academic work interesting. So Davis asked "How do theories which are generally considered interesting differ from theories which are generally considered non-interesting?"

He came up with a very straightforward answer: "Interesting theories are those which deny certain assumptions of their audience, while non-interesting theories are those which affirm certain assumptions of their audience".

The way Davis argued for his proposition is both amusing and insightful reading. He makes a very convincing case for the provocative proposition that the impact of academic work is depending not primarily on its truth, but there is something else. He says "Those who carefully and exhaustively verify trivial theories are soon forgotten". Through a series of examples, he shows that we tend to remember and appreciate work more which somehow challenges taken for granted knowledge (like a maxim, a presumed common-place truth, a widely accepted practice).

P. Klaus ( $\square)$

Nurnberg, Germany

e-mail: peter.klaus@wiso.uni-erlangen.de
For us, the editors working to develop Logistics Research into a broadly recognized high-quality academic journal for our field; there are two important messages in Davis' proposition which we would like to pass on to our authors and readers: First, it is not only the academic rigor of a piece of research that makes it a widely recognized contribution. Manuscripts should be "interesting" from their readers' perspective-which requires some understanding of the prior knowledge and mindset of the intended audience. The choice of research questions and the presentation of research findings in a field of the applied sciences must stand the "so what?", "who cares?", "why bother", and "what good is it" tests. Secondly, as a consequence for those who do understand what it is "that's interesting" in research, there is a dangerous temptation to be avoided: If research is "made" to be interesting artificially by the use of provocative, attention-seeking wording, or even by the manipulation of evidence, it looses its scientific authenticity. We must make efforts to do both-to be academically rigorous and authentic and to be interesting!

In this issue of our journal, we have five original paper contributions. Three of these touch on a subject which currently receives a lot of attention, particularly among logistics researchers with an engineering background: It is the issue of decentralized, "autonomous" controls in those very complex logistical systems where centralized planning and centralized organizational arrangements are reaching their limits. The paper by Falkenberg/Overmeyer/ Ventz/Krühn proposes an innovative modular system for many intra-plant logistics operations. The paper by Nopper/Ten Hompel analyzes the cost advantages of selforganizing airport baggage handling systems-where the cost of RFID-tags over traditional baggage tags have to be compensated-from a life-cycle perspective. Mayer, in an 
invited paper which received the BVL scientific paper award, presents his research on deadlock prevention in industrial materials flow systems-again based on the application of modular, locally controlled conveyor units.

The other two papers in this issue are examples from other parts of Logistics Research's interdisciplinary spectrum of topics: Perttula presents a case study, which analyzes problems of safety and damage in international logistics chains. Last not least, Visser in her paper shows through a Stated Preference experiment how-otherwise often neglected-behavioral factors like trust, confidentiality, and commitment influence collaboration decisions in logistics.

I hope you will find this interesting reading!

Peter Klaus

Editor-in-Chief: Logistics Research

October 2010 